\title{
Max Planck: closures will damage German science
}

\section{Cosmochemistry and geochemistry departments should continue their innovative work.}

Sir - Your News story "Max Planck plans double blow to chemistry" (Nature 422, $105 ; 2003)$, reporting that the Max Planck Society is seriously considering closing its departments of cosmochemistry and geochemistry in Mainz, is most disturbing. Insofar as the Max Planck Society is concerned with pursuing cutting-edge scientific research programmes, such action is difficult to understand.

Research in cosmochemistry is a vital laboratory activity, linked with astrophysics and observational astronomy. It has active and strong connections to study of the early chemical evolution of the Universe, cosmology, and the Solar System's formation and evolution. Important pioneering work, both in terms of new discoveries and the development of new generations of instruments, is being carried out under the direction of Günter Lugmair and is the focus of widespread and active interest. Cosmochemistry is an intellectually and technically exciting area and will continue to be so during the next few decades.

The area of terrestrial geochemistry has grown enormously in terms of the depth of understanding of the chemical processes related to Earth's structure and dynamics and of the geophysics of Earth's thermochemical and dynamical engine. There are important new possibilities in studies of environmental geochemistry, both in measurements and in theory, that are key to understanding the migration of elements, not only in Earth's deep interior, but also in its near-surface aqueous environments. A whole new array of techniques and instrumental approaches are now being developed, some being pioneered at Mainz under the leadership of Albrecht Hofmann.

The absence of these research areas from the Max Planck Society's science programme will, in our view, have a devastating effect on the level of science in Germany and will be negative for the rest of Europe. There is no doubt that some restructuring of German research is needed for fiscal and management reasons. However, closing leading institutes that are doing vital and innovative research is an action that we must deplore.

G. J. Wasserburg ${ }^{\star}$, D. P. McKenzie $\dagger$

*USA Division of Geological and Planetary Sciences, California Institute of Technology, Pasadena California 91125, USA

$\dagger$ Department of Earth Sciences, University of Cambridge, Cambridge CB3 OEZ, UK

\section{Max Planck: cuts were decided years ago}

Sir - In your News story "Max Planck plans double blow to chemistry" (Nature 422, 105; 2003), you state that two departments at the Max Planck Institute for Chemistry in Mainz are the "first casualties of a budget freeze" at the Max Planck Society. This is not correct.

The closure of one department was decided years ago and has nothing to do with the present budget constraints of the Max Planck Society. The federal consolidation programme, aimed at reducing staff numbers in former West German institutes, has obliged the Max Planck Institute for Chemistry to cut 25 staff positions. This includes eliminating Professor Günter Lugmair's position when he retires in 2005

The institute's further development has to be seen within the context of the overall development of the Max Planck Society. Within this context, the institute is free to set its own scientific priorities, which include the continued use of the ion microprobe pictured in your story. Bernd Wirsing

Max Planck Society Press Office, Postfach 1010 62, 80084 München, Germany

Our reporter contacted the Max Planck Society's press office as well as the heads of departments at the Institute of Chemistry in Mainz. None of these told him that the closure of the cosmochemistry department had been decided several years ago - Editor, Nature

\section{Leading edge lasers}

Sir - Your News in Brief story "Spending spree gives German physics a high-energy boost" (Nature 421, 682; 2003) reported that free-electron lasers generate intense $\mathrm{X}$-ray radiation for the study of molecules during chemical reactions. In fact, these lasers have operated from the microwave to the vacuum ultraviolet and can be used to study not only molecules but atoms, condensed matter, plasmas and even elementary particles via Compton backscattering. Thanks to their performance advantages, which include tunability, pulse brevity, high repetition rate, capacity for pump-probe synchronization with other light sources, and high average and peak powers, the development of free-electron lasers is being advanced on many fronts. Swapan Chattopadhyay

Thomas Jefferson National Accelerator Facility, 12000 Jefferson Avenue, Newport News, Virginia 23606, USA

\section{Vigilance is vital to avoid conflicts of interest}

Sir - Rahul K. Dhanda makes an excellent point in his Correspondence "Time for bioethics and business to start talking" (Nature 421, 573; 2003): the separation between bioethicists and biotechnologists constitutes a risk to both groups, as well as to the public good. He overstates, however, the potential for synergy.

The rift between bioethicists and the biotech industry is not just cultural, as Dhanda suggests, but also functional. Bioethicists have a social role that is sometimes at odds with the goals (and social role) of industry. The public expects bioethicists to offer independent, reasoned commentary on complex issues in healthcare and the life sciences. Nowhere is such commentary more crucial than in the rapidly expanding realm of biotechnology. Surely Dhanda would agree that unreflective collaboration with industry would hinder the ability of bioethics to meet this expectation.

It is true that bioethicists have often been preoccupied by questions of how they can maintain their integrity if working with industry. But what Dhanda calls "endless discussions over conflicts of interest" are, I fear, a necessity. Bioethicists need to carry on this discussion, but as well as including industry they must also try to determine what sorts of engagement with industry are least likely to corrode public trust in bioethics, and what kinds of structural safeguards are possible.

The Enron scandal taught us that the accounting profession must become more vigilant in its struggle to avoid conflicts of interest, and indeed may need to consider significant structural reforms if the profession is to retain its useful role in the functioning of financial systems. Similarly, bioethicists should not stop talking about conflict of interest: vigilance on this count is the discipline's only hope of continuing to merit the public's trust.

\section{Chris MacDonald}

Department of Philosophy, Saint Mary's University, Halifax, Nova Scotia B3H 3C3, Canada 